\title{
Effects of X-ray Radiation on Oat Seed
}

\author{
Raul Abrams ${ }^{2}$
}

\section{INTRODUCTION}

Exposing seed to high dosages of $\mathrm{X}$-rays usually has a twofold effect: 1, Many of the seed fail to produce seedlings, and 2, the seedlings produced are stunted. The germination percentage of small-grain seed treated with a given X-ray dosage can be modified by different factors. Froier and Gustafsson $(3)^{3}$ found that large seed of Kolben and Velvet wheat varieties germinated better than small seed when both were treated with 10,000 r and 20,000 r of X-rays. Working with barley, Gelin (4) showed that seed containing 15 percent of moisture when treated with $\mathrm{X}$-rays germinated only one-half as well as those with 10 percent of moisture when treated.

Caldecott (1) showed that increasing the X-ray dosage given to barley seed caused greater stunting of the resultant seedlings. In another study, Caldecott (2) found that the sensitivity of barley seed to X-rays, measured by seedling heights 7 days after planting, decreased when the seed moisture content was raised from 4 to 8 percent. However, between 8 and 16 percent there was little change in radio sensitivity. He adjusted the moisture content of the barley seed by keeping them in desiccators with different relative humidities.

\section{OBJECTIVE}

This study was conducted to determine the effect of several factors upon the X-ray sensitivity of oat seed. The sensitivity was measured by germination percentages and seedling weights and heights 14 days after planting. The factors investigated were:

1. The effect of recurrent X-ray treatment of the seed in one, two, and three successive generations.

2. The relative sensitivity of the seed of several oat varieties produced under nearly identical environmental conditions.

${ }^{1}$ A thesis submitted to the Graduate Faculty of Iowa State College in partial fulfillment of the requirements for the degree of Master of Science.

2 Research Assistant in Agronomy, Agricultural Experiment Station, University of Puerto Rico, Río Piedras, P. R. The author wishes to express his appreciation to Dr. K. J. Frey for his helpful guidance throughout the conduct of this study and in the preparation of the thesis; to Dr. T. W. Horner for his advice on the statistical treatment of the data; and to Drs. J. W. Gowen and J. Stadler for their assistance in the radiation of the experimental material.

${ }^{3}$ Italic numbers in parentheses refer to Literature Cited, p. 258. 
3. The effect of seed size when the production environment and genotype were similar.

\section{MATERIALS AND METHODS}

The appropriate seed moisture contents and X-ray dosages were determined from a preliminary greenhouse experiment using Bonham variety. Seed lots were adjusted to three moisture percentages, 5.0,13.8, and 18.2, by keeping the seed for 2 weeks in desiccators over solutions of concentrated sulfuric acid, saturated sodium chloride solution, and water, respectively. The seed from each moisture level were divided into five samples which were treated with $15,000,20,000,25,000,30,000$, and $40,000 \mathrm{r}$ of $\mathrm{X}$-rays, respectively.

The seed were radiated with a G. E. Maxitron X-ray machine operated at $250 \mathrm{kvp}$. and $30 \mathrm{ma}$. The radiation was filtered through a $0.25-\mathrm{mm}$. $\mathrm{Cu}+\mathrm{Al}$ filter. The dose rate was $1,305 \mathrm{r}$ per minute and the distance from the anode to the center of the target was approximately $15.5 \mathrm{~cm}$. The seed were radiated in a plastic container with four compartments; thus three or four lots of seed with different moisture levels were treated with the same dosage simultaneously.

Within 24 hours after the radiation treatment the oat seed were planted in flats in the greenhouse. A plot consisted of 100 seed sown one-half inch deep in a sterilized mixture of soil, sand, and peat, in a ratio of $2: 1: 1$. The experimental design was a randomized block with three replications and nonradiated seed, used as a check, were included four times in each replication.

Germination percentages and plant heights, in centimeters, were determined for each plot 14 days after planting. On the same day the seedlings were cut at the soil surface, dried at $30^{\circ} \mathrm{C}$., and weighed. The dry weights were adjusted to weight per 100 seedlings in grams.

The average germination percentages, plant heights, and weights per 100 seedlings from this experiment are presented in table 1.

On the basis of these data, two moisture percentages and two X-ray dosages were selected for subsequent experiments. They were 13.8 and 18.2 percent of moisture treated with 40,000 or $30,000 \mathrm{r}$ of $\mathrm{X}$-rays, respectively. Each of these combinations reduced the germination percentage to approximately three-fourths, the plant heights to one-third, and the weight per 100 seedlings to one-fourth of the corresponding values in the checks.

To study the effect of recurrent radiation in successive seed generations the six oat varieties, Simcoe, Park, Bonham, Mo. O-205, C.I. 6748, and Clintland were used. The previous radiation history for all of the varieties 
was as follows:

Sample No
1
2
3
4

3954

1955

$25,000 \mathrm{r}$
$25,000 \mathrm{r}$
None
None

$25,000 \mathrm{r}$

None

$25,000 \mathrm{r}$

None

Seed from one variety at a time were tempered to the proper moisture content, ${ }^{4}$ radiated, sown in the greenhouse, and measured for germination

TABLE 1.-Plant heights and dry weights per 100 seedlings, and germination and moisture percentages of oat seed of Bonham variety treated with different

$X$-ray dosages

\begin{tabular}{c|c|c|c|c}
\hline $\begin{array}{c}\text { X-ray dosage } \\
\text { (roentgens) }\end{array}$ & Moisture content & Germination & Plant height & $\begin{array}{c}\text { Dry weight per } \\
\text { 100 seedlings }\end{array}$ \\
\cline { 2 - 3 } & Percent & Percent & Cm. & Grams \\
\cline { 2 - 3 } 15,000 & 5.0 & 16.2 & 5.0 & 0.36 \\
15,000 & 13.8 & 99.0 & 20.4 & 1.79 \\
15,000 & 18.2 & 98.6 & 19.4 & 1.63 \\
20,000 & 5.0 & 16.2 & 5.5 & .38 \\
20,000 & 13.8 & 96.8 & 19.5 & 1.61 \\
20,000 & 18.2 & 96.6 & 16.8 & 1.33 \\
25,000 & 5.0 & 22.2 & 6.8 & .43 \\
25,000 & 13.8 & 97.2 & 17.5 & 1.37 \\
25,000 & 18.2 & 89.4 & 11.1 & .95 \\
30,000 & 5.0 & 19.6 & 5.6 & .37 \\
30,000 & 13.8 & 94.0 & 13.6 & 1.07 \\
30,000 & 18.2 & 68.2 & 7.9 & .52 \\
40,000 & 5.0 & 11.6 & 3.9 & .21 \\
40,000 & 13.8 & 72.4 & 7.7 & .43 \\
40,000 & 18.2 & 14.4 & 2.9 & .18 \\
0 & 5.0 & 97.0 & 20.8 & 1.87 \\
0 & 13.8 & 97.8 & 21.5 & 2.11 \\
0 & 18.2 & 91.0 & 21.3 & 1.94 \\
\hline
\end{tabular}

percentage, and seedling heights and weights in the same way as in the preliminary experiment.

Seed of Mo. O-205, Clintland, Bonham, and Park varieties with no previous radiation history were used to determine the relative sensitivity of different oat varieties to radiation.

The recurrent radiation and variety experiments were repeated in the field in 1956. The moisture contents of the seed subjected to radiation

- The moisture content of seed kept over water and saturated sodium chloride solution varied from 19.4 to 21.5 and from 14.0 to 15.6 percent, respectively, in the different experiments. 
were approximately the same for the field as for the greenhouse experiments, but the radiation dosages were reduced from 30,000 to $20,000 \mathrm{r}$, and from 40,000 to $30,000 \mathrm{r}$ for the high- and low-moisture seed lots, respectively. The X-ray dosages were reduced for the field-planted material because previous experience had shown that planting in the field resulted in a lower germination percentage for any given dosage than planting in the greenhouse. Presumably, this was because of more adverse environmental conditions in the field.

Another radiation experiment was conducted in the field using primary and secondary kernels of the oat varieties Mo. O-205, Clintland, Bonham, and Park to determine the effect of seed size on sensitivity to X-rays.

For the field tests of the recurrent radiation material each variety was sown in a separate experiment. Each experiment was arranged in a completely randomized design with the following entries: 1, Each combination of moisture content and radiation dosage included three times; 2, laboratory-dried samples of each seed lot with previous radiation history included three times; 3, samples of seed tempered over water and concentrated sodium chloride solution included once each. A plot consisted of 4 rows, 8 feet long. In each row 25 treated seed were space-planted approximately 4 inches apart in the row, making a total of 100 seed per plot. The total numbers of field experiments and plots were 11 and 391, respectively. The plant-survival percentages were determined for each of the field plots 6 weeks after planting.

All of the oat seed used in these experiments were grown in the same field on the Agronomy Farm at Ames, Iowa, in 1955. Consequently, any differential effects upon sensitivity caused by the environment where the seed were produced were at a minimum.

\section{EXPERIMENTAL RESULTS}

\section{RECURRENT RADIATION EXPERIMENTS}

The germination percentages from the recurrent radiation experiments grown in the greenhouse are presented in table 2. The frequency distributions of the germination percentage data were skewed, so they were transformed to arc sines for the analyses of variance computations. Pertinent mean squares from analyses of the transformed data are given in table 3.

Holding the oat seed in a desiccator over water for 2 weeks was detrimental to their viability. The germination was reduced from 10.0 percent in Bonham to 35.0 percent in C. I. 6748. However, holding the seed over a saturated sodium chloride solution had no appreciable effect on viability except in Park and Simcoe varieties. The reduction in germination in these varieties was approximately 14.0 and 20.0 percent, respectively. 
TABLE 2.-Germination percentages of seed of 6 oat varieties treated with $X$-rays for differing numbers of successive generations and grown in the greenhouse

\begin{tabular}{|c|c|c|c|c|c|c|c|c|c|}
\hline \multicolumn{3}{|c|}{$X$-ray dosage ${ }^{1}(r)$} & \multicolumn{6}{|c|}{ Germination percentage for- } & \multirow{2}{*}{ Mean } \\
\hline 1954 & 1955 & 1956 & Clintland $^{2}$ & C.I.67482 & Bonham & Park ${ }^{3}$ & Mo. 0-2054 & Simcoes & \\
\hline 一 & - & 30 & 21.7 & 1.0 & 0 & 49.0 & 3.3 & 15.0 & 15.0 \\
\hline - & 25 & 30 & 33.7 & 15.0 & 1.0 & 70.7 & 40.7 & 8.0 & 32.2 \\
\hline 25 & 25 & 30 & 19.7 & 38.0 & 4.3 & 62.0 & 0 & 22.0 & 24.8 \\
\hline 25 & - & 30 & 6.3 & 6.3 & 29.7 & 89.3 & 4.0 & 30.7 & 27.1 \\
\hline (6) & & & 82.0 & 63.3 & 88.0 & 80.3 & 76.0 & 82.0 & 77.9 \\
\hline- & 一 & 40 & 81.7 & 96.3 & 61.7 & 87.0 & 73.0 & 83.3 & 80.5 \\
\hline - & 25 & 40 & 80.3 & 95.7 & 32.7 & 79.3 & 63.3 & 61.7 & 68.8 \\
\hline 25 & 25 & 40 & 75.3 & 94.0 & 47.0 & 71.7 & 40.0 & 35.7 & 60.6 \\
\hline 25 & - & 40 & 87.0 & 92.7 & 47.0 & 87.0 & 64.7 & 77.0 & 75.9 \\
\hline (6) & & & 98.0 & 98.0 & 95.3 & 84.7 & 97.0 & 76.7 & 91.6 \\
\hline$(6,7)$ & & & 98.3 & 98.7 & 98.8 & 98.7 & 97.3 & 96.4 & 98.0 \\
\hline
\end{tabular}

1 The 3 zeros have been omitted from each dosage.

2 Seed treated with 30,000 and $40,000 \mathrm{r}$ of X-rays contained 21.5 and 14.7 percent of moisture, respectively.

${ }^{3}$ Seed treated with 30,000 and $40,000 \mathrm{r}$ of $\mathrm{X}$-rays contained 21.1 and 15.6 percent of moisture, respectively.

4 Seed treated with 30,000 and 40,000 r of X-rays contained 19.5 and 14.1 percent of moisture, respectively.

5 First 5 germination percentages were from seed with 4.4 percent of moisture and treated with $25,000 \mathrm{r}$ of X-rays. Seed treated with $40,000 \mathrm{r}$ of X-ray contained 14.5 percent of moisture.

${ }^{6}$ Check.

${ }^{7}$ Laboratory-dried seed contained approximately 8.5 percent of moisture.

TABLE 3.-Mean squares from analyses of variance of arc sine transformation of germination percentages of seed of 6 oat varieties treated with $X$-rays for differing numbers of successive generations

\begin{tabular}{l|c|c|c|r|r|r|r}
\hline \multicolumn{1}{c|}{ Source of variation } & $\begin{array}{c}\text { Degrees } \\
\text { of } \\
\text { freedom }\end{array}$ & \multicolumn{7}{|c}{ Mean squares' for- } \\
\cline { 3 - 7 } & & Clintland & C.I. 6748 & Bonham & Park & Mo. 0-205 & Simcoe \\
\hline Among checks & 2 & $46.5^{* *}$ & $14.15^{* *}$ & $248^{* *}$ & $838^{* *}$ & $507^{* *}$ & $563^{* *}$ \\
Check vs. radiation & 1 & $13,314^{* *}$ & $10,869^{* *}$ & $29,528^{* *}$ & $3,545^{* *}$ & $20,434^{* *}$ & $13,480^{* *}$ \\
30,000 r vs. 40,000 r & 1 & $9,058^{* *}$ & $19,625^{* *}$ & $5,708^{* *}$ & $477^{* *}$ & $7,678^{* *}$ & $5,052^{* *}$ \\
Within 30,000 r & 3 & $239^{* *}$ & $601^{* *}$ & $603^{* *}$ & $381^{* *}$ & $857^{* *}$ & $160^{* *}$ \\
Within 40,000 r & 3 & 38 & 14 & 218 & $99^{*}$ & $209^{* *}$ & $513^{* *}$ \\
Error & $29^{3}$ & 25 & 28 & 113 & 27 & 17 & $26^{4}$ \\
\hline
\end{tabular}

$1 *$ Denotes significance at the 5-percent level; ${ }^{* *}$ denotes significance at the 1 -percent level.

2 For Simcoe variety the 30,000-r treatment was replaced with $25,000 \mathrm{r}$.

${ }^{3} 20$ d.f. from $R \times T$ interaction and 9 d.f. from plots within checks.

128 d.f. 
For every combination of variety and previous radiation treatment the seed with approximately 20.0 percent of moisture, and treated with 30,000 $\mathrm{r}$ of X-ray, produced lower germination percentages than those treated with $40,000 \mathrm{r}$ at approximately 14.0 percent of moisture. The 40,000-r dosage caused the least damage to seed viability in C. I. 6748, which was reduced in germination only 2.0 to 6.0 percent, while Park was the least sensitive variety to the $30,000-\mathrm{r}$ dosage. The most sensitive varieties to the latter dosage were Bonham and Mo. 0-205. In two seed lots, one from each of these varieties, none of the seed germinated.

According to the mean squares in table 3 , there were highly significant differences among the means of the transformed data for the seed lots within the 30,000-r treatment for every variety. In C. I. 6748 and Bonham the seed lots receiving $\mathrm{X}$-rays only once gave the lowest germination percentage, those receiving radiation in two successive generations were intermediate, and those with three successive generations of $\mathrm{X}$-ray treatment produced the highest germination. This suggests a build-up in resistance to lethality caused by radiation. However, in Clintland, Park, and Mo. 0-205 the seed lots with two successive generations of radiation produced the highest germination percentages, those radiated only once were intermediate, and the seed samples were lowest after three successive generations of radiation. The mean germination percentages for all varieties when undergoing treatment with $30,000 \mathrm{r}$ of $\mathrm{X}$-rays were $15.0,32.2$, and 24.8 for the seed lots which were radiated in one, two, and three successive generations. This does not indicate any consistent gain in resistance or sensitivity to radiation through repeated treatments with $\mathrm{X}$-rays.

The mean squares indicate that there were significant differences among the means of the transformed data of the seed lots within the 40,000-r treatment for three of the varieties: Park, Mo. O-205, and Simcoe. In these varieties, and Clintland, the germination percentages were highest for the seed lots radiated only once, intermediate for those radiated in two successive generations, and lowest for those radiated in three. This would indicate an increase in sensitivity to radiation with recurrent $\mathrm{X}$-ray treatment. In C. I. 6748 variety there was virtually no difference in germination among the three seed lots, and in Bonham the results were inconclusive. The mean germination percentages for all of the varieties when treated with $40,000 \mathrm{r}$ were 80.5, 68.8, and 60.6 for the seed lots which were radiated for one, two, and three successive generations, respectively.

The germination percentages for the recurrent radiation experiments growing in the field and the mean squares computed from the data, are presented in tables 4 and 5 , respectively. These data are similar to those from the 40,000-r treatments in the greenhouse experiments. Tempering the oat seed over water for 2 weeks lowered the germination percentage 
TABLE 4.-Germination percentages of seed of 6 oat varieties treated with $X$-rays for differing numbers of successive generations and grown in the field at Ames, Iowa

\begin{tabular}{|c|c|c|c|c|c|c|c|c|c|}
\hline \multicolumn{3}{|c|}{$X$-ray dosage' $(r)$} & \multicolumn{6}{|c|}{ Germination percentage for- } & \multirow{2}{*}{ Mean } \\
\hline 1954 & 1955 & 1956 & Clintland 2 & C.I. 67482 & Bonham & Park ${ }^{2}$ & Mo. O-205t & Simcoe 5 & \\
\hline - & - & 20 & 32.3 & 64.3 & 12.7 & 23.7 & 60.0 & 47.7 & 40.1 \\
\hline - & 25 & 20 & 21.3 & 24.3 & 17.3 & 22.0 & 53.0 & 46.3 & 30.7 \\
\hline 25 & 25 & 20 & 25.3 & 34.7 & 3.7 & 24.7 & 46.0 & 18.3 & 25.4 \\
\hline 25 & - & 20 & 1.7 & 33.3 & 57.0 & 10.3 & 47.7 & 32.7 & 32.1 \\
\hline (6) & & & 63.5 & 66.8 & 66.8 & 53.3 & 83.5 & 68.7 & 67.1 \\
\hline- & - & 30 & 71.0 & 73.3 & 59.0 & 80.3 & 77.7 & 68.7 & 71.7 \\
\hline - & 25 & 30 & 64.3 & 69.0 & 70.7 & 82.0 & 61.0 & 66.0 & 68.8 \\
\hline 25 & 25 & 30 & 59.0 & 66.0 & 52.7 & 78.0 & 64.3 & 64.3 & 64.1 \\
\hline 25 & - & 30 & 73.3 & 67.0 & 59.0 & 80.3 & 79.0 & 78.0 & 72.3 \\
\hline (6) & & & 86.3 & 84.8 & 80.8 & 84.5 & 83.5 & 86.0 & 84.3 \\
\hline$(0,7)$ & & & 82.9 & 84.6 & 81.4 & 85.8 & 82.0 & 82.3 & 83.2 \\
\hline
\end{tabular}

1 The 3 zeros have been omitted from each figure.

2 Seed treated with 20,000 and $30,000 \mathrm{r}$ of X-rays contained 31.8 and 14.7 percent of moisture, respectively.

${ }^{3}$ Seed treated with 20,000 and 30,000 r of X-rays contained 22.0 and 13.7 percent of moisture, respectively.

${ }^{4}$ Seed treated with 20,000 and 30,000 r of X-rays contained 18.6 and 13.1 percent of moisture, respectively.

${ }^{5}$ Seed treated with 20,000 and $30,000 \mathrm{r}$ of X-rays contained 22.4 and 14.0 percent of moisture, respectively.

${ }^{B}$ Check.

${ }^{7}$ Laboratory-dried sample contained approximately 8.5 percent of moisture.

TABLE 5.-Mean squares from analyses of variance of germination percentages of seed of 6 oat varieties treated with $X$-rays for differing numbers of successive generations and grown in the field at Ames, Iowa

\begin{tabular}{l|r|r|r|r|r|r|r}
\hline \multicolumn{1}{c|}{ Source of variation } & $\begin{array}{c}\text { Degrees of } \\
\text { freedom }\end{array}$ & \multicolumn{7}{|c}{ Mean squares' for- } \\
\cline { 2 - 7 } & & Clintland & C.I. 6748 & Bonham & Park & Mo. 0-205 & Simcoe \\
\hline Among checks & 2 & $673^{* *}$ & $511^{* *}$ & $469^{* *}$ & $1,660^{* *}$ & 2 & $393^{* *}$ \\
Check vs. radiation & 1 & $14,263^{* *}$ & $7,982^{* *}$ & $14,570^{* *}$ & $9,069^{* *}$ & $5,069^{* *}$ & $7,745^{* *}$ \\
20,000 r vs. 30,000 r & 1 & $13,114^{* *}$ & $5,281^{* *}$ & $8,513^{* *}$ & $21,600^{* *}$ & $2,128^{* *}$ & $6,534^{* *}$ \\
Within 20,000 r & 3 & 518 & $908^{* *}$ & $1,668^{* *}$ & $133^{*}$ & $119^{*}$ & $566^{* *}$ \\
Within 30,000 r & 3 & $127^{*}$ & 32 & $169^{*}$ & 8 & $251^{* *}$ & $111^{* *}$ \\
Error & 30 & 30 & 32 & $38^{2}$ & 41 & $40^{2}$ & $32^{3}$ \\
\hline
\end{tabular}

1* Denotes significance at the 5-percent level; ** denotes significance at the 1-percent level.

228 d.f.

29 d.f. 
markedly, and in general, the germination of the check seed lots was from 10 to 15 percent lower in the field than in the greenhouse.

Although there were some discrepancies in the data, the germination percentages tended to be lowest in the seed lots which had been radiated for three generations, intermediate in those radiated during two successive generations, and highest in those radiated in only one. For the 20,000-r treatment the mean germination percentages for the six varieties were $40.1,30.7$, and 25.4 for the seed lots radiated in one, two, and three successive generations, respectively. With the treatment of $30,000 \mathrm{r}$, the corresponding values were $71.7,68.8$ and 64.1 , respectively.

In three of the four combinations of radiation and seed moisture content, i.e., the 40,000-r series in the greenhouse experiments, and the 20,000and 30,000-r series in the field experiments, the data indicated that recurrent X-radiation of oat seed in successive generations tended to increase their radio sensitivity when measured as the number of seed killed.

It appears from both the field and greenhouse experiments that one generation without $\mathrm{X}$-ray treatment between two radiated generations was sufficient to increase the germination percentage to the level of that for seed with no previous radiation history.

The average seedling heights from the recurrent radiation experiments grown in the greenhouse are presented in table 6. Holding the oat seed over water in a desiccator for 2 weeks reduced the seedling heights in all varieties, except Bonham and Park. However, seed held over a saturated sodium chloride solution produced seedlings with no appreciable reduction in plant height, except for Mo. O-205.

In every variety seed containing approximately 20.0 percent of moisture, and treated with $30,000 \mathrm{r}$ of X-ray, produced seedlings with lower plant heights than those treated with $40,000 \mathrm{r}$ at approximately 14.0 percent of moisture. The variety least affected in plant height at both $\mathrm{X}$-ray dosages was Park, with an average reduction of $3.0 \mathrm{~cm}$. The most sensitive variety was Bonham.

With the 30,000-r treatment the mean seedling heights of the six varieties were $4.1,5.7$, and $6.6 \mathrm{~cm}$. from the seed lots radiated for one, two, and three successive generations, respectively. This suggests that some resistance to the effects of X-ray treatment had been developed by recurrent radiation. If so, the resistance was lost when one nonradiated generation was interposed between two radiated generations. All of the seed lots, irrespective of previous radiation history, produced seedlings with mean heights between 7.0 , and $7.5 \mathrm{~cm}$. when treated with $40,000 \mathrm{r}$.

The weights per 100 seedlings from the recurrent radiation experiments 
grown in the greenhouse are presented in table 7 and the pertinent mean squares from the analyses of variance of these data are given in table 8 .

The weights per 100 seedlings from seed tempered over either water or sodium chloride were reduced when compared to the laboratory-dried check in all varieties, except Bonham and Park. For these two varieties

TABLE 6.-Plant heights (cm.) of seedlings grown in the greenhouse from seed of 6 oat varieties treated with $X$-rays for differing numbers of successive generations

\begin{tabular}{|c|c|c|c|c|c|c|c|c|c|}
\hline \multicolumn{3}{|c|}{$X$-ray dosagel $(r)$} & \multicolumn{6}{|c|}{ Plant heights for- } & \multirow{2}{*}{ Mean } \\
\hline 1954 & 1955 & 1956 & Clintland $^{2}$ & C.I. $6748^{2}$ & Bonham? & Park & Mo. 0-2054| & Simcoes & \\
\hline - & - & 30 & 3.8 & 0.8 & 0 & 7.8 & 2.2 & 6.1 & $4.1^{6}$ \\
\hline - & 25 & 30 & 4.9 & 5.2 & 1.0 & 9.8 & 7.8 & 5.6 & 5.7 \\
\hline 25 & 25 & 30 & 5.6 & 4.3 & 6.2 & 10.0 & 0 & 6.8 & $6.6^{6}$ \\
\hline 25 & - & 30 & 3.3 & 1.6 & 3.8 & 11.4 & 4.0 & 6.1 & 5.0 \\
\hline (7) & & & 12.5 & 9.6 & 11.9 & 13.3 & 10.5 & 13.0 & 11.8 \\
\hline- & - & 40 & 7.4 & 8.0 & 4.6 & 9.9 & 6.4 & 8.5 & 7.5 \\
\hline- & 25 & 40 & 8.4 & 8.2 & 4.4 & 10.6 & 4.5 & 6.2 & 7.1 \\
\hline 25 & 25 & 40 & 7.8 & 7.7 & 6.8 & 10.1 & 6.0 & 5.2 & 7.3 \\
\hline 25 & - & 40 & 8.3 & 7.2 & 3.9 & 11.2 & 4.5 & 6.7 & 7.0 \\
\hline (7) & & & 13.6 & 9.9 & 11.8 & 12.8 & 11.0 & 14.0 & 12.2 \\
\hline$(7,8)$ & & & 13.8 & 10.3 & 12.0 & 12.7 & 15.0 & 14.0 & 13.0 \\
\hline
\end{tabular}

1 The 3 zeros have been omitted from each dosage.

2 Seed treated with $30,000 \mathrm{r}$ and $40,000 \mathrm{r}$ of X-rays contained 21.5 and 14.7 percent of moisture, respectively.

${ }^{3}$ Seed treated with $30,000 \mathrm{r}$ and $40,000 \mathrm{r}$ of $\mathrm{X}$-rays contained 21.1 and 15.6 percent of moisture, respectively.

4 Seed treated with $30,000 \mathrm{r}$ and $40,000 \mathrm{r}$ of $\mathrm{X}$-rays contained 19.5 and 14.1 percent of moisture, respectively.

5 First 5 germination percentages were from seed with 4.4 percent of moisture and treated with $25,000 \mathrm{r}$ of $\mathrm{X}$-ray. Seed treated with $40,000 \mathrm{r}$ of $\mathrm{X}$-rays contained 14.5 percent of moisture.

- Mean of 5 varieties.

7 Check.

${ }^{8}$ Laboratory-dried seed contained approximately 8.5 percent of moisture.

the seedling vigor was greater. However, only in Park, Mo. O-205, and Simcoe, were the differences among check means significant.

In nearly every comparison the 30,000-r treatment applied to seed containing approximately 20.0 percent of moisture caused a greater reduction in seedling vigor than the 40,000-r treatment did on drier seeds.

The mean squares indicate significant differences in weights per 100 seedlings from seed lots within the 30,000-r treatment for four of the varieties: Clintland, C. I. 6748, Park, and Mo. O-205. In the Clintland, C. I. 
6748 , and Mo. $0-205$ varieties the seedlings from seed lots receiving two successive generations of radiation were highest in weight per 100 seedlings, while in Park, Simcoe, and Bonham, those with three X-ray treatments produced the heaviest seedlings. In no case did the seed treated only once

TABLE 7.-Dry weights (grams) per 100 seedlings of 6 oat varieties treated with $X$-rays for differing numbers of successive generations and grown in the greenhouse

\begin{tabular}{|c|c|c|c|c|c|c|c|c|c|}
\hline \multicolumn{3}{|c|}{ X-ray dosage' (r) } & \multicolumn{6}{|c|}{ Weight per 100 seedlings of- } & \multirow{2}{*}{ Mean } \\
\hline 1954 & 1955 & 1956 & $\begin{array}{l}\text { Clint- } \\
\text { land } 2\end{array}$ & C.I. $6748^{2}$ & Bonham ${ }^{2}$ & Park 8 & $\begin{array}{c}\text { Mo. } \\
\text { O-2054 }\end{array}$ & Simcoe 5 & \\
\hline - & - & 30 & 0.287 & 0.060 & 0 & 0.443 & 0.273 & 0.549 & $0.322^{8}$ \\
\hline 一 & 25 & 30 & .331 & .397 & .125 & .675 & .592 & .461 & .430 \\
\hline 25 & 25 & 30 & .275 & .344 & .410 & .901 & 0 & .638 & $.514^{6}$ \\
\hline 25 & - & 30 & .217 & .138 & .587 & .904 & .402 & .536 & .464 \\
\hline (7) & & & .984 & .938 & 1.107 & 1.085 & .754 & .941 & .968 \\
\hline 一 & - & 40 & .560 & .780 & .414 & .747 & .432 & .648 & .599 \\
\hline - & 25 & 40 & .714 & .782 & .290 & .738 & .369 & .511 & .567 \\
\hline 25 & 25 & 40 & .508 & .658 & .486 & .767 & .445 & .494 & .560 \\
\hline 25 & - & 40 & .565 & .613 & .322 & .920 & .440 & .613 & .579 \\
\hline (7) & & & 1.010 & .994 & 1.134 & .947 & .895 & .757 & .956 \\
\hline$(7,8)$ & & & 1.074 & 1.088 & 1.058 & .867 & 1.021 & 1.065 & 1.028 \\
\hline
\end{tabular}

1 The 3 zeros have been omitted from each dosage.

${ }^{2}$ Seed treated with 30,000 and $40,000 \mathrm{r}$ of $\mathrm{X}$-rays contained 21.5 and 14.7 percent of moisture, respectively.

${ }^{3}$ Seed treated with 30,000 and $40,000 \mathrm{r}$ of $\mathrm{X}$-rays contained 21.1 and 15.6 percent of moisture, respectively.

${ }^{4}$ Seed treated with 30,000 and 40,000 r of X-rays contained 19.5 and 14.1 percent of moisture, respectively.

${ }^{5}$ First 5 germination percentages were from seed with 4.4 percent of moisture and treated with $25,000 \mathrm{r}$ of $\mathrm{X}$-ray. Seed treated with $40,000 \mathrm{r}$ of $\mathrm{X}$-rays contained 14.5 percent of moisture.

6 Mean of 5 varieties.

7 Check.

${ }^{8}$ Laboratory-dried seed contained approximately 8.5 percent of moisture.

produce the heaviest seedlings. The mean weights per 100 seedlings for all varieties when treated with $30,000 \mathrm{r}$ of X-rays were $0.322,0.430$, and 0.514 from the seed lots radiated in one, two, and three successive generations, respectively. These data indicate, in general, that seedlings produced from seed radiated in two or three successive generations were more vigorous than those from seed radiated only once.

In only one variety, Clintland, were there significant differences in the mean weights per 100 seedlings from seed lots within the 40,000-r treat- 
TABLE 8.-Mean squares from analyses of variance of weights (grams) per hundred seedlings of oat varieties treated with $X$-ray for different numbers of successive generations and grown in the greenhouse

\begin{tabular}{l|c|c|c|c|c|c|c}
\hline \multicolumn{1}{c|}{ Source of variation } & $\begin{array}{c}\text { Degrees of } \\
\text { freedom }\end{array}$ & \multicolumn{6}{|c}{ Mean squaresi for- } \\
\cline { 2 - 7 } & & Clintland & C.I. 6748 & Bonham & Park & Mo. 0-205 & Simcoe \\
\hline Among checks & 2 & 0.016 & 0.018 & 0.008 & $0.059^{*}$ & $0.092^{* *}$ & $0.119^{* *}$ \\
Check vs. radiation & 1 & $3.008^{* *}$ & $2.128^{* *}$ & $3.930^{* *}$ & $.246^{* *}$ & $2.756^{* *}$ & $1.977^{* *}$ \\
30,000 r vs. 40,000 r & 1 & .465 & .898 & .058 & .023 & .000 & .004 \\
Within 30,000 r & 3 & $.018^{*}$ & $.056^{*}$ & $.047^{2}$ & $.145^{* *}$ & $.078^{* * 3}$ & .019 \\
Within 40,000 r & 3 & $.024^{*}$ & .024 & .024 & .022 & .004 & .017 \\
Error & $29^{4}$ & .006 & $.017^{5}$ & $.025^{6}$ & .016 & .007 & $.021^{7}$ \\
\hline
\end{tabular}

1* Denotes significance at the 5 -percent level; ${ }^{* *}$ denotes significance at the 1 percent level.

21 d.f.

22 d.f.

420 d.f. from $R \times T$ interaction and 9 d.f. from plots within checks were pooled.

27 d.f.

625 d.f.

728 d.f.

ment. The mean weights per 100 seedlings for the six varieties treated with $40,000 \mathrm{r}$ were $0.599,0.567$, and 0.560 for the seedlings from seed lots radiated for one, two, and three successive generations, respectively.

\section{VARIETY EXPERIMENTS}

The mean germination percentages, plant heights, and dry weights per 100 seedlings from the greenhouse experiment, and the mean germination percentages from the field experiment are presented in tables 9 and 10, respectively. The analyses of variance of the transformed germinationpercentage data from these two experiments are given in tables 11 and 12 respectively. In both experiments the seed with the high moisture content and receiving the 30,000-r and 20,000-r X-ray dosage produced the lowest germination percentages.

In the greenhouse experiment the germination of all varieties when treated with $40,000 \mathrm{r}$ was over 90 percent, indicating little effect from this treatment. With the 30,000-r dosage Simcoe germinated 78.2 percent while Mo. 0-205 and Bonham germinated only 23.0 and 33.4 percent, respectively. Bonham appeared to be the most sensitive variety to radiation in the field experiment.

Simcoe and Mo. 0-205 were reduced the most in plant height by the 40,000-r treatment, but Bonham and Mo. O-205 produced the shortest 
TABLE 9.-Moisture and germination percentages, plant heights, and dry weights per 100 seedlings, for the seed of oat varieties Mo. O-205, Bonham, Simcoe, and Park treated with different $X$-ray dosages, and grown in the greenhouse

\begin{tabular}{l|c|c|c|c|c}
\hline \multicolumn{1}{c|}{ Variety } & $\begin{array}{c}\text { X-ray } \\
\text { dosage' }(\mathrm{r})\end{array}$ & $\begin{array}{c}\text { Moisture } \\
\text { content }\end{array}$ & Germination & Plant height & $\begin{array}{c}\text { Dry weight per } \\
\text { 100 seedlings }\end{array}$ \\
\cline { 2 - 3 } & & Percent & Percent & \multicolumn{1}{c}{ Cm. } & Grams \\
Mo. O-205 & 30 & 20.5 & 23.0 & 4.2 & 0.355 \\
Bonham & 30 & 20.3 & 33.4 & 4.5 & .417 \\
Simcoe & 30 & 20.7 & 78.2 & 7.4 & .645 \\
Park & 30 & 21.5 & 62.6 & 7.4 & .863 \\
Mo. O-205 & 40 & 15.5 & 96.6 & 8.2 & .688 \\
Bonham & 40 & 15.1 & 94.4 & 11.8 & 1.150 \\
Simcoe & 40 & 15.7 & 91.0 & 7.7 & .806 \\
Park & 40 & 15.0 & 100.0 & 9.7 & 1.088 \\
Mo. O-205 & 0 & 8.4 & 98.8 & 13.8 & 1.294 \\
Bonham & 0 & 8.6 & 96.8 & 14.4 & 1.645 \\
Simcoe & 0 & 8.5 & 98.6 & 14.4 & 1.355 \\
Park & 0 & 8.3 & 100.0 & 13.3 & 1.450 \\
\hline
\end{tabular}

1 Thousands of roentgen units.

TABLE 10.-Moisture and germination percentages for the seed of oat varieties of Mo. $0-205$, Bonham, Simcoe and Park, treated with differing $X$-ray dosages, and grown in the field in 1956

\begin{tabular}{l|c|c|c}
\hline Variety & X-ray dosagel $(r)$ & Moisture content & Germination \\
\cline { 2 - 3 } & & Percent & Percent \\
Mo. O-205 & 20 & 19.1 & 27.3 \\
Bonham & 20 & 20.8 & 9.0 \\
Simcoe & 20 & 20.0 & 44.7 \\
Park & 20 & 20.8 & 31.0 \\
Mo. O-205 & 30 & 13.7 & 71.0 \\
Bonham & 30 & 13.8 & 39.7 \\
Simcoe & 30 & 13.7 & 69.7 \\
Park & 30 & 14.3 & 84.0 \\
Mo. O-205 & 0 & 8.3 & 90.7 \\
Bonham & 0 & 8.6 & 84.7 \\
Simcoe & 0 & 8.4 & 84.0 \\
Park & 0 & 8.2 & 82.3 \\
\hline
\end{tabular}

1 Thousands of roentgen units.

seedlings at the $30,000-\mathrm{r}$ dosage. With the 40,000-r dosage the weights per 100 seedlings were reduced for all varieties, but their rank from the lowest to highest was the same as the checks, indicating a similar reaction for all varieties. However, at the 30,000-r treatment, Bonham, which produced the greatest weight per 100 seedlings in the check, was more affected 
than either Park or Simcoe. This conclusion was substantiated by the mean squares in table 11. There was not a high significant interaction among the varieties in the " $40,000 \mathrm{r}$ vs. check" comparison, but the interaction was highly significant in the " $30,000 \mathrm{r}$ vs. others" comparison.

In spite of some discrepancies in the data it appears that Park and Simcoe varieties were more resistant than Bonham to damage caused by $\mathrm{X}$-ray

TABLE 11.-Analyses of variance of the arc sine transformations of germination percentages of oat seed of 4 oat varieties, treated with different $X$-ray dosages and planted in the greenhouse

\begin{tabular}{|c|c|c|}
\hline Source of variation & Degrees of freedom & Mean squares' \\
\hline $\begin{array}{l}\text { Varieties } \\
\text { Treatments } \\
\text { Varieties } \times \text { treatments } \\
40,000 \mathrm{r} \text { vs. check } \\
30,000 \mathrm{r} \text { vs. others } \\
\text { Error }\end{array}$ & $\begin{array}{ll}3 & \\
2 & \\
6 & \\
& 3 \\
& 3 \\
44 & \end{array}$ & $\begin{array}{c}630^{* *} \\
9,769^{* *} \\
448^{* *} \\
53^{*} \\
844^{* *} \\
14\end{array}$ \\
\hline
\end{tabular}

$1 *$ Denotes significance at the 5 -percent level; ${ }^{* *}$ denotes significance at the 1-percent level.

TABLE 12.-Analysis of variance of the arc sine transformations of germination percentages of oat seed of 5 oat varieties, treated with different $X$-ray dosages and planted in the field

\begin{tabular}{l|c|c}
\hline \multicolumn{1}{c|}{ Source of variation } & Degrees of freedom & Mean sqquares' \\
\hline Varieties & 3 & $964^{* *}$ \\
Treatments, X-rays & 2 & $10,241^{* *}$ \\
Varieties X treatments & 6 & $389^{* *}$ \\
30,000 r vs. check & 3 & $562^{* *}$ \\
20,000 r vs. others & 3 & $216^{* *}$ \\
Error & 24 & 24 \\
\hline
\end{tabular}

1** Denotes significance at the 1-percent level.

treatment of seeds. Mo. $0-205$ reacted as a sensitive variety in the greenhouse experiment, but as a resistant one in the field.

\section{PRIMARY VS. SECONDARY SEED}

The average germination percentages of the primary and secondary oat seed of four varieties treated with different X-ray dosages are presented in table 13. The analyses of variance from these data are given in table 14.

Within varieties the untreated primary and secondary seed germinated 
virtually the same. The secondary seed of Mo. 0-205, Bonham, and Simcoe varieties germinated better than the primary when treated with 20,000 r. Conversely, for Park variety the primary seed germinated better than the secondaries. At the 30,000-r dosage the primary and secondary seed

TABLE 13.-Germination percentages of primary and secondary seed of 4 oat varieties treated with different $X$-ray dosgaes and grown in the field

\begin{tabular}{l|c|c|c|c|c}
\hline \multicolumn{1}{c|}{ Seed used } & $\begin{array}{c}\text { X-ray } \\
\text { dosage' }(r)\end{array}$ & $\begin{array}{c}\text { Mo. O-205 } \\
\text { Germination }\end{array}$ & $\begin{array}{c}\text { Bonham } \\
\text { germination }\end{array}$ & $\begin{array}{c}\text { Simcoe } \\
\text { germination }\end{array}$ & $\begin{array}{c}\text { Park } \\
\text { germination }\end{array}$ \\
\cline { 2 - 2 } & 20 & 25.7 & 16.7 & 18.7 & 68.7 \\
Primary & 20 & 31.3 & 40.0 & 58.0 & 42.7 \\
Secondary & 30 & 69.7 & 39.0 & 63.3 & 81.7 \\
Primary & 30 & 66.7 & 59.0 & 65.3 & 86.3 \\
Secondary & 0 & 87.7 & 86.7 & 87.3 & 92.0 \\
Primary (check) & 0 & 84.7 & 86.3 & 89.7 & 91.0 \\
Secondary (check) & 0 & &
\end{tabular}

1 The 3 zeros have been omitted from each dosage.

TABLE 14.-Analyses of variance of germination percentages of primary and secondary seed of 4 oat varieties treated with differing $X$-ray dosages and planted in the field

\begin{tabular}{|c|c|c|c|c|c|}
\hline \multirow{2}{*}{ Source of variation } & \multirow{2}{*}{$\begin{array}{l}\text { Degrees of } \\
\text { freedom }\end{array}$} & \multicolumn{4}{|c|}{ Mean squares' for- } \\
\hline & & Mo. 0-205 & Bonham & Simcoe & Park \\
\hline Among treatments & 5 & $10,520 * *$ & $23,718^{* *}$ & $9,888^{* *}$ & $* 5,334^{* *}$ \\
\hline $20,000 \mathrm{r}$ vs. $30,000 \mathrm{r}$ & 1 & $4,720^{* *}$ & $1,302^{* *}$ & $2,028 * *$ & $* 2,408^{* *}$ \\
\hline $\begin{array}{l}\text { Primary } 20,000 \mathrm{r} \text { vs. secondary } \\
20,000 \mathrm{r}\end{array}$ & 1 & 48 & $816^{* *}$ & $2,302 * *$ & $* 1,014^{* *}$ \\
\hline $\begin{array}{l}\text { Primary } 30,000 \mathrm{r} \text { vs. secondary } \\
30,000 \mathrm{r}\end{array}$ & 1 & 13 & $620^{* *}$ & 6 & 32 \\
\hline Primary check vs. secondary check & 1 & 13 & 0 & 8 & 0 \\
\hline Check vs. irradiation treatments & 1 & $5,725^{* *}$ & $9,120^{* *}$ & $5,525^{* *}$ & * $1,879 * *$ \\
\hline Error & 12 & 15 & 23 & 9 & 19 \\
\hline
\end{tabular}

1 ** Denotes significance at the 1-percent level.

produced approximately the same germination percentages in Mo. O-205, Simcoe, and Park, but the secondary seed of Bonham germinated better than the primaries.

No general conclusions can be drawn from this experiment, but it appears that for Bonham variety the small seed were less sensitive to $\mathrm{X}$-ray treatment than were the large. This conclusion is at variance with that of Froier and Gustafsson (4) who found that small wheat seed were more sensitive to X-ray treatment than large ones. 


\section{DISCUSSION}

The results reported herein indicate that recurrently radiating oat seed in successive generations tended to increase their sensitivity to $\mathrm{X}$-ray treatment when measured by the number of seed killed. This result might be explained as due to an increase in the frequency of induced lethal mutations or chromosomal disturbances caused by successive generations being exposed to X-ray treatment.

Exposing seed to high X-ray dosages increases the mutation rate and many of these mutations are lethal. In some cases the lethal effect is immediate and the seed fail to germinate in the $\mathrm{X}_{1}$ generation, while in others it is recessive and the effect is shown only in later generations in self-pollinated crops. If a recessive lethal mutation in the heterozygous condition were present in an $\mathrm{X}_{1}$ seed, another $\mathrm{X}$-ray treatment might cause a mutation in the other gene at that locus and result in lower germination of the seed. A possible indication of this is the finding that one nonradiated generation between two radiated generations was sufficient to restore the germination percentage to the level of that for seed with no previous radiation history.

The plant heights and seedling vigor data when treated with 40,000 r gave similar results to those obtained with the germination data. However, the results were contradictory with $30,000 \mathrm{r}$. The mean plant heights and seedling vigor indicated that the seedlings produced from seed radiated during two or three successive generations were taller and more vigorous than those from seed radiated only once. Perhaps there was a physiological variation between the individual cells of the seed which was greater in the seed treated once than in those with previous radiation history. Presumably this could result in a faster recovery from X-ray damage in the seedlings from seed radiated in two or three successive generations than in those radiated in only one.

For all experiments, the seed with high moisture content and low X-ray dosage produced the lowest germination percentages, and the plant heights and seedling vigor were reduced most. This could be explained by assuming that increased moisture content caused greater metabolic activity, and thus greater sensitivity to radiation.

The data from this study indicate that Park and Simcoe varieties were more resistant than Bonham to the damage caused by $\mathrm{X}$-ray treatment of the seed. A possible explanation for these varietal reactions may be the inherent chemical composition of the seed of the different varieties. Another possibility may be differences in the thickness of the seed hulls. Thicker hulls might reduce the degree of penetration of $\mathrm{X}$-rays and also 
the damage caused by radiation. Further studies should be made on these points.

\section{SUMMARY}

In a study involving the treatment of oat seed of six varieties-Simcoe, Park, Bonham, Mo. 0-205, C. I. 6748, and Chintland, with high X-ray dosages, the data indicated that:

1. Recurrent radiation of oat seed in successive generations tended to increase their sensitivity to X-ray treatment when measured by the number of seed killed.

2. Seedlings produced from seed radiated in two or three successive generations were taller and more vigorous than those from seed radiated only once, when the X-ray dosage was $30,000 \mathrm{r}$ and the seed moisture content was approximately 20 percent. With an X-ray dosage of $40,000 \mathrm{r}$ and a seed moisture content of approximately 14 percent the plant heights and seedling vigor from all seed lots were virtually the same.

3. The seed with the high moisture content and lowest X-ray dosage produced the lowest germination percentages and underwent the greatest reduction in plant heights and seedling vigor.

4. Four oat varieties-Mo. 0-205, Bonham, Simcoe, and Park-produced under similar environmental conditions differed in their sensitivity to X-ray damage.

\section{RESUMEN}

Un estudio de los tratamientos de semillas de avena con fuertes aplicaciones de rayos $\mathrm{X}$ reveló lo siguiente:

1. Las radiaciones recurrentes de las semillas de avena a través de generaciones sucesivas propendieron a aumentar su sensibilidad a los rayos $X$ cuando ésta se midió por el número de semillas anuladas.

2. Las plantas producidos de semillas irradiadas en 2 ó 3 generaciones sucesivas resultaron más altas y vigorosas que aquellos nacidos de semillas irradiadas una sola vez, cuando la dosis aplicada fué de $30,000 \mathrm{r}$ de rayos $\mathrm{X}$ y el contenido de humedad en la semilla era de aproximadamente 20 por ciento. Con una aplicación de 40,000 r y un contenido de humedad en la semilla de aproximadamente 14 por ciento, el crecimiento y vigor de las plantas fué virtualmente el mismo en todos los lotes.

3. Las semillas con un alto contenido de humedad que fueron tratadas con la dosis más baja de rayos $\mathrm{X}$ produjeron el por ciento de germinación más bajo y la mayor reducción en el crecimiento y vigor de las plantas.

4. Cuatro variedades de avena producidas bajo condiciones ambientales similares demostraron diferentes grados de sensibilidad a los efectos dañinos de los rayos $\mathrm{X}$. 


\section{LITERATURE CITED}

1. Caldecott, Richard, S., Effects of ionizing radiations on seeds of barley, Radiation Res. 2 339-50, 1955.

2. - Effects of hydration on $\mathrm{X}$-ray sensitivity in Hordeum, Radiation Res. 3 316-30, 1955.

3. Froier, $\mathbf{K}$, and Gustafsson, A., The influence of seed size and hulls on X-ray susceptibility in cereals, Hereditas 30 583-9, 1941.

4. Gelin, Olov. E. V., The cytological effect of different seed treatments in X-rayed barley, Heredilas 27 209-19, 1941. 